\title{
Impact of Staff Qualification and Training on Performance of the Core Function Activities (CFA) of the Communicable Disease Surveillance System, Gazera State, Sudan, 2009
}

\author{
Magda A. Nogodalla* and Ahmed I. Abdelghani \\ Epidemiology Department, Ministry of Health, Khartoum, Sudan
}

\section{Objective}

The aim of this study is to assess the impact of staff qualification and training on the performance of Core Function Activities (CFA) Of Communicable Disease Surveillance System in Gazera State, Sudan.

\section{Introduction}

This study assessed the performance of the core function activities (CFA) of the Communicable Disease Surveillance system and response (CDSs) existing in Gazera State. The first assessment of disease surveillance being conducted in the area during 2008-2009. The assessment findings facilitate the identification of exact areas for improvement and consequently was used in surveillance system improvement as well as a baseline for future reform plans (1).

Communicable diseases in Gazera State continue to be the leading cause of morbidity and mortality (2). The State was one of the states that experienced epidemics of serious diseases such as Acute Watery Diarrhoea, Cerebro-spinal Meningitis, Rift valley Fever..etc. During the last decade, the state has witnessed more than twenty epidemics resulting in high morbidity and mortalities, as reported in 2006-2007(1). This was coupled with struggling health services and health information system and this was stated in the Federal Ministry of Health (FMOH) annual report 2008 (2).

\section{Methods}

A descriptive cross sectional facility based study was done. The assessment covered all: 51 sentinel sites, seven locality offices and all the staff of state epidemiology directorate, during the period 2008 2009. The study included the structure, facilities, personnel, resources and records of the system. Tools used for data collection included: Questionnaires for key informants, and checklist for different sites. In addition to that, a review of all documents was conducted. This was done to find out whether there is association between the assessed variables. The collected data was cleaned, entered, analyzed and processed using SPSS V.11. The relationship between dependent and independent variables was determined using chi2 test.

\section{Results}

The study revealed that there was a deficiency in CDSs Core Function Activities, especially at locality levels. This can be shown in the assessed staff training and qualification required in surveillance Core Function Activities of the surveillance system (Basic training required in surveillance (77\%), skills (38\%), knowledge-awareness (43\%), immediate data reporting (57\%), weekly data reporting (67\%), manuals utilization (69\%), use of standard case definition forms (63\%) and feedback (57\%)). In addition to a strong positive associations between staff qualification and training with CFA; knowledge (Chi=23.05 - $\mathrm{p}=0.01)$, awareness $(\mathrm{Chi}=21.17, \mathrm{p}=0.002)$, reporting timelines $(\mathrm{Chi}=10.2-\mathrm{p}=0.03)$

The study concluded that there were significant relations that can highlight the areas that are in need for strengthening.

\section{Conclusions}

The study concluded that there were significant relations that can highlight the areas in need for strengthening, as a top priority for Gazera State Surveillance system improvement and for improving future reform plans. This can be achieved by: encouraging the hiring of qualified and competent staff, capacity building for state trainer in disease surveillance, utilization of standard forms, manual and standard operation procedures, revision and updating of the National Guidelines and training materials. And finally, health authorities should pay more attention to improve the lower level of the surveillance system, particularly locality levels

\section{Keywords}

Disease Surveillance; communicable diseases surveillance; assessment; Sudan

\section{Acknowledgments}

My deepest thanks are expressed to my research supervisor for being an excellent advisor, editor and critic. Dr: Elsadig Mahguob Eltayeb, the National Coordinator for AFP surveillance, Expanded Program on Immunization, for his support and guidance in promoting and leading the necessary steps in different phases without which the achievements would not have been possible.

\section{References}

1.Annual epidemiological report, Directorate General of Preventive Medicine, Epidemiology department, health information unit, Federal Ministry of health (FMOH), Sudan.2007.

2.Talal el Fadil. An interventional study to strengthen the national communicable disease surveillance and response system in Sudan, 20012002, Khartoum State Ministry of health, General Directorate for planning, Research Direction .Biannual Research News Letters, October 2004

*Magda A. Nogodalla

E-mail: sarajuja@yahoo.com 